BNL 852 (I-338)

322
8128164

\title{
A HIGH CAPACITY DIGITAL DATA HANDLING SYSTEM FOR USE WITH COUNTER HODOSCOPES AND DIGITIZED SPARK CHAMBERS IN ON-LINE COMPUTER AGS EXPERIMENTS
}

K.J. FOLEY, W. HiginBOTHAM, S.J. LINDENBAUM, W.A. LOVE,

S. OZaKI, D. PotTer, and L.C.L. Yuan

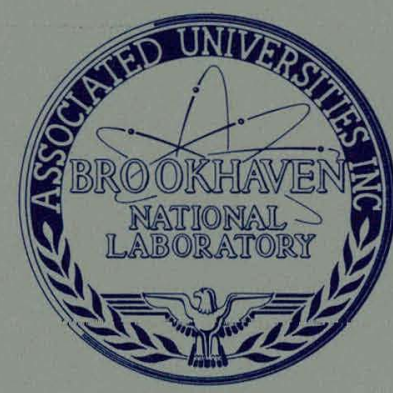

March 1, 1964

BROOKHAVEN NATIONAL LABORATORY

ASSOCIATED UNIVERSITIES, INC.

under contract with the

UNITED STATES ATOMIC ENERGY COMMISSION 


\section{DISCLAIMER}

This report was prepared as an account of work sponsored by an agency of the United States Government. Neither the United States Government nor any agency Thereof, nor any of their employees, makes any warranty, express or implied, or assumes any legal liability or responsibility for the accuracy, completeness, or usefulness of any information, apparatus, product, or process disclosed, or represents that its use would not infringe privately owned rights. Reference herein to any specific commercial product, process, or service by trade name, trademark, manufacturer, or otherwise does not necessarily constitute or imply its endorsement, recommendation, or favoring by the United States Government or any agency thereof. The views and opinions of authors expressed herein do not necessarily state or reflect those of the United States Government or any agency thereof. 


\section{DISCLAIMER}

Portions of this document may be illegible in electronic image products. Images are produced from the best available original document. 


\section{A HIGH CAPACITY DIGITAL DATA HANDLING SYSTEM FOR USE WITH COUNTER HODOSCOPES AND DIGITIZED SPARK CHAMBERS IN ON-LINE COMPUTER AGS EXPERIMENTS}

K.J. Foley, W. Higinbotham, S.J. Lindenbaum, W.A. LoVE, S. OZAKI, D. POTTER, AND L.C.L. YUAN

March 1, 1964

BROOKHAVEN NATIONAL. LABORATORY UPTON, NEW YORK 


\section{E G A L NOTICE}

This report was prepared as an account of Government sponsired work. Neiller lle United States, nor the Commission, nor any person acting on behalf of the Commission:

A. Makes any warranty or representation, expressed or implied, with respect to the accuracy, completeness, or usefulness of the information contained in this report, or that the use of any information, apparatus, micthod, or proccss discloscd in this rcport may not infringe privately owned rights; or

$\bar{B}$. Assumes any liabilities with respect to the use of, or for damages resulting from the use of any information, apparatus, method, or process disclosed in this report.

As used in the above, "person acting on behalf of the Commission" includes any employee or contractor of the Commission, or employee of such contractor, to the extent that such employee or contractor of the Commission, or employee of such contractor prepares, disseminates, or provides access to, any information pursuant to his employment or contrast with the Commission, or his employment with surh contractor.

\section{PRINTED IN USA}

PRICE 50 CENTS

Available from the Office of Technical Services

Department of Commerce Washington 25, D.C. 


\section{A HIGH CAPACITY DIGITAL DATA HANDLING SYSTEM FOR USE WITH COUNTER HODOSCOPES AND DIGITIZED SPARK CHAMBERS IN ON-LINE COMPUTER AGS EXPERIMENTS}

Our use of a counter hodoscope system with a digital data handler and on-line computer for AGS experiments on elastic scattering of elementary particles at high energy has been previously described.* As indicated, even in this first and conceptually simplest of the new breed of counter experiments generated by this technique, the size of the digital data handler was a severe limit on the performance of the experiment. The 96 input bits were fewer than the number of counters used, and coding was necessary to reduce the number of bits required to describe an event. Furthermore, in many cases in which the incident beam rate was high, more events could have been gathered than the 32 per pulse allowed by the depth of the memory. This means that although with the first unit* more than 50,000 events/hr were handled, sometimes $\sim 500,000$ to $1,000,000$ events/hr could have been obtained with sufficient memory capacity. As a matter of fact, these limitations were known for a considerable period before the beginning of the previously described series of experiments, and plans had already been made for an expanded digital data handling system having a bit capacity greater by about two orders of magnitude and cxpanded both in depth and in number of bits per event. Since it is considerably cheaper to expand the memory depth than the word length, a basic unit was chosen with 48 input bits and a memory depth of 4096 words. The necessary expansion in inputs per event is achieved by breaking an event too large to store in one memory word into an ordered series of words and then stacking them in the memory in sequence (up to 15 times) until the entire event is stored. Of course, this results in a loss of speed, but with the short cycle time of 3.5 microseconds attained, this is not an important limitation.

*Foley, Lindenbaum, Love, Ozaki, Russell, and Yuan, Phys. Rev. Letters 10, 376 (1963); 11, 425 (1963); A counter hodoscope digital data handling and on-line computer system used in high energy scattering experiments, Nucl. Instr. Methods, in press.
The question might be raised: why have a digital data handling system at all rather than going on line directly to the computer input? The latter certainly could be done in principle, but a separate data handling system has several major advantages. First, it provides for a magnetic tape record of the experiment and allows the experiment to proceed independent of the condition of the direct data link or of the computer. Second, no major hardware change is necessary to change to another computer. Third, the system provides for buffering in future applications which may involve time sharing of a computer.

In this paper the new digital data handling system is described, and its application to experiments planned shortly for the Brookhaven AGS is outlined.

The new data handling system at present consists of 200 fast gates, two of the $48 \times 4096$-bit memory units with associated electronics, two high speed magnetic tape transports, and a direct data link to the Merlin computer. Figure 1 shows a block diagram of the system. Figures 2, 3, and 4 are photographs of the system in the data trailcr.

\section{THE FAST GATES}

The scintillation hodoscope counter signals must be gated in fast coincidence with the signal identifying the event of interest in order to reduce the accidental rates to manageable levels. The fast gate circuit has a 2-ma input threshold. The gating pulse is provided by cascaded fourfold fan-out circuits driven by a discriminator whose output pulse width can be easily adjusted. Delay cables may be inserted to alter the timing of the gates (in groups of four). The minimum available gate width is 6.5 nsec. A coincidence signal sets a tunnel diode in the gate circuit which stores the information temporarily until it can be transferred to the memory. 


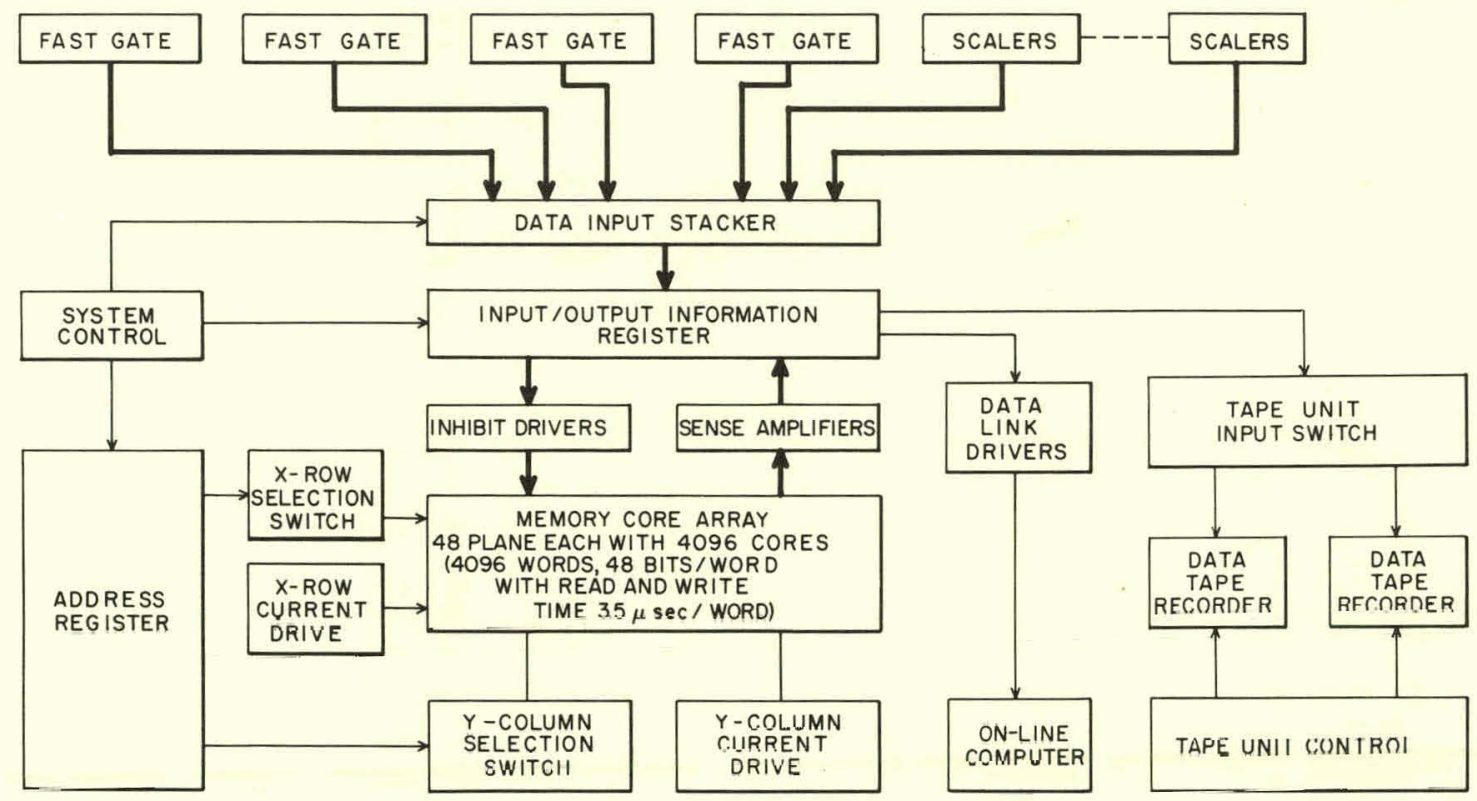

Figure 1. A block diagram of the new digital data handling system.

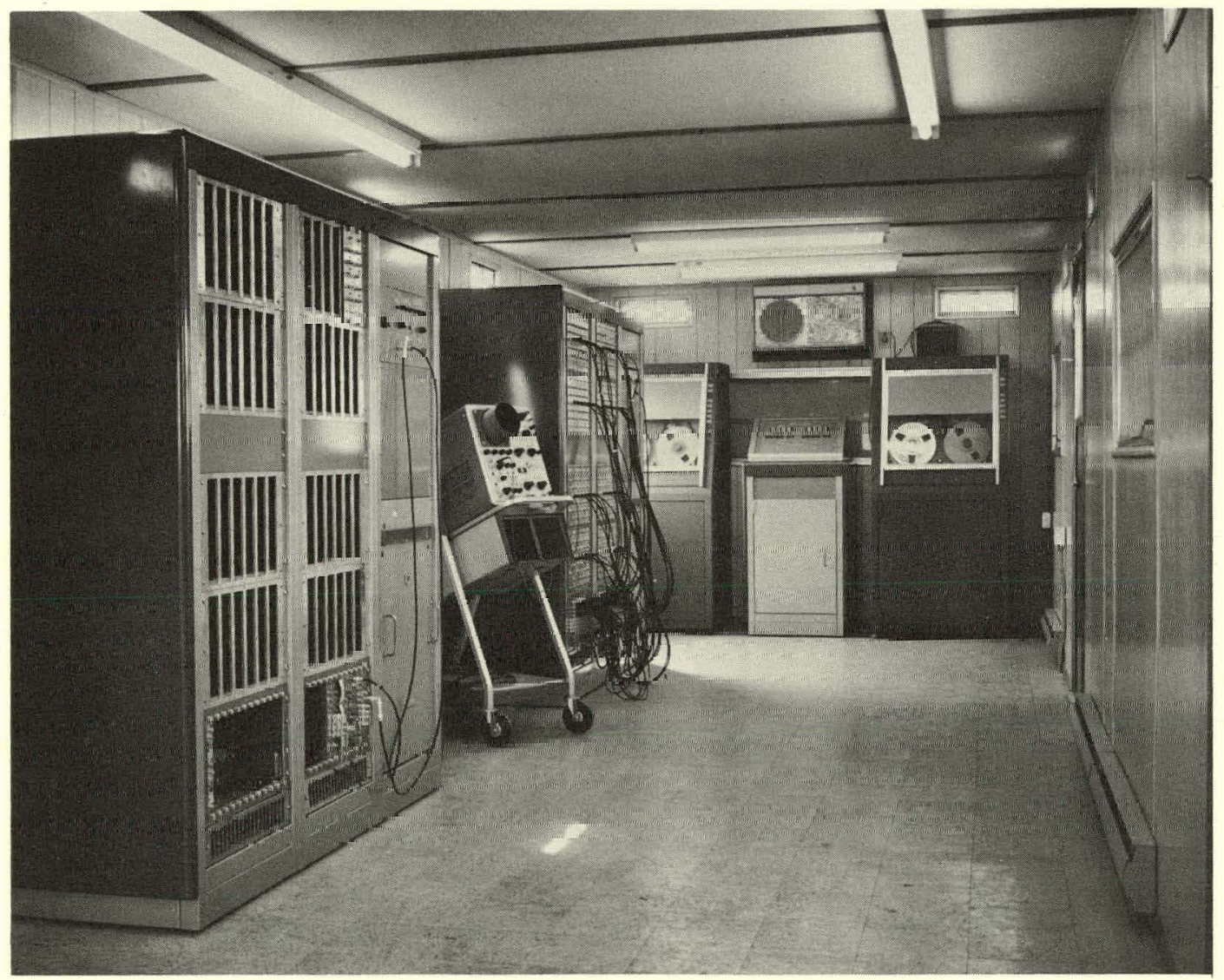

Figure 2. The data handling system trailer. 


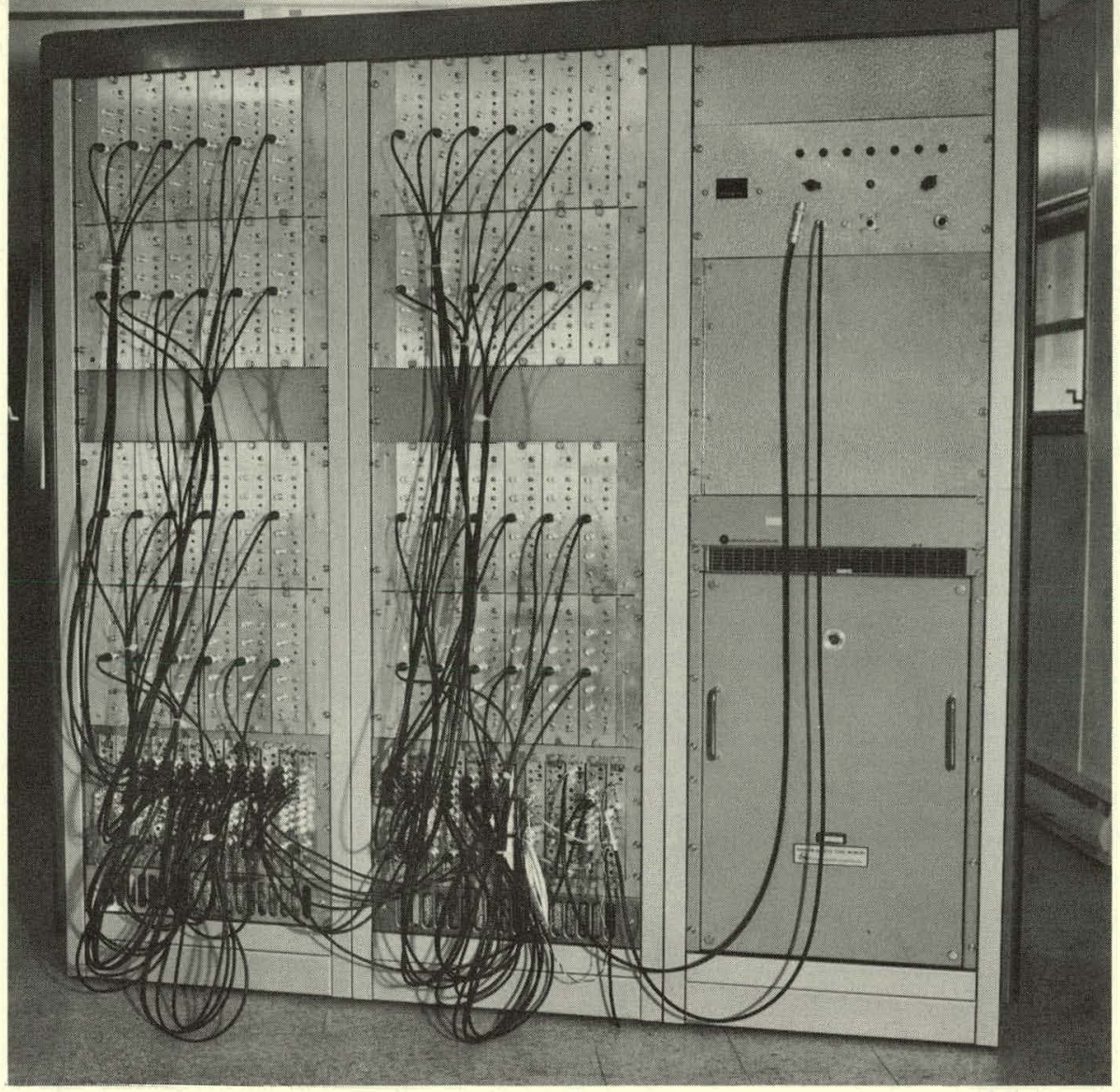

Figure 3. The data handling system, front view.

Figure 4. The tape transports, front view.

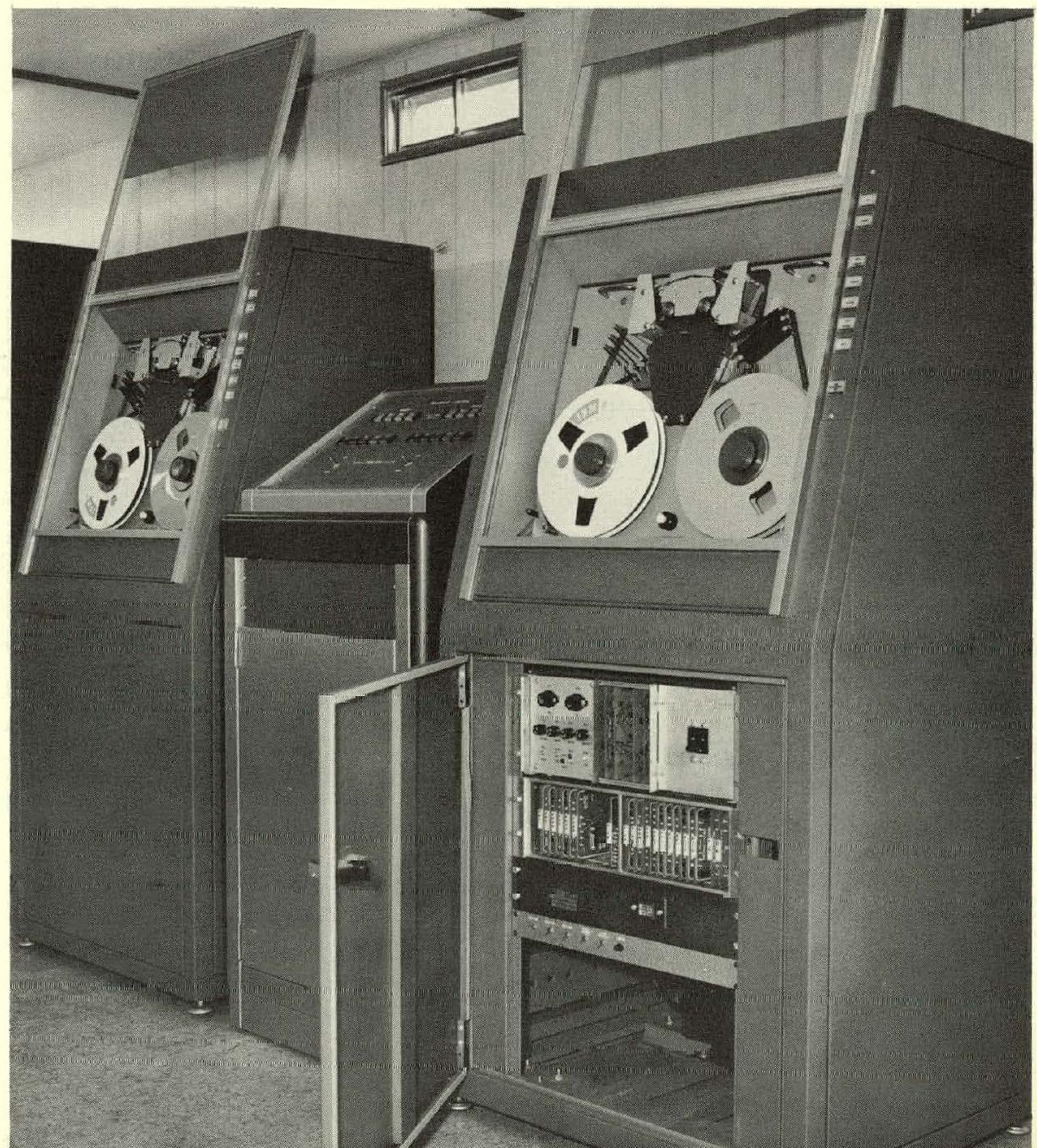




\section{THE DATA STACKER}

The words/event decoder output is controlled by a front panel switch to provide for storage of up to 15 words/event in memory.

The input word commutator is driven by the words/ event decoder and provides signals to drive the input word mixer, stepping through the successive word inputs.

The input word mixer consists of 48 cards, one corresponding to each bit of a word, each containing 6 AND gates. One input of each AND gate is brought out to an input word connector, the other input of each AND circuit is enabled by the input word commutator at that time chosen to write the associated word. This provides inputs for 6 words, the first 4 being used by the fast gates (192 bits). By repeated loading of the 6 th input, up to 10 words can be stored through this channel which, along with the 5th word input, provides, for example, for eleven 48-bit words of sonic chamber or wire chamber track location information.

\section{THE MEMORY UNIT}

The memory is a Computer Control Corporation Model TCM-30, 4096-word $\times$ 48-bit, random access, coincidence current unit. Full cycle time is $6 \mu \mathrm{sec}$. Split-cycle operation (read only or write only) takes only $3.5 \mu \mathrm{sec}$, and this mode is used in this system. The memory consists of a $64 \times 64$-core plane for each of the 48 bits (see Figure 5). During the write time a half write current in one $x$ and one $y$ wire sets the core at the intersection of these wires to the " 1 " state. If a " 0 " is to be written in the core selected, an "inhibit" wire which threads all the cores in the plane is pulsed with a half write current in the opposite sense, reducing the net current below the " 1 " writing level. Reading is accomplished by driving one $x$ and one $y$ wire with half write currents in a direction opposite to that during the write cycle. This resets to the " 0 " state those cores set to " 1 " during the write cycle, inducing a current in the correspnnding sense lines. The read cycle is destructive, essentially clearing the memory to " 0 " as it proceeds.

The input-output informalion register is composed of 48 flipflops which control the inhibit drivers during writing and which during reading receive the memory information from the sense lines.

During the write cycle the output of the input word mixer is transferred to the information reg- ister, setting the flipflops to the " 0 " or " 1 " condition. During the read cycle, the output of the sense amplifiers delivers the information from the memory in parallel into this 48 -bit register. The flipflops are also wired as six 8-bit shift registers. During the read cycle the output word is shifted 8 times to provide eight 6 -bit characters for transmission to tape and to the computer.

The address register holds a 12-bit address which determines which $x$ and $y$ wires are to be driven during the read and write operations. This information is provided by a 12-bit up-down scaler in the system control logic.

\section{SYSTEM CONTROL LOGIC}

This control circuit switches and resets the input circuitry, controls and addresses the memory, slats and stups the magnetic tapc transport, controls the writing of tape, and drives the data link. It contains the address scaler, special word input gating, write and read control, parity generator, and output driver.

The up-dowen address scaler is a 12-bit binary scaler which provides the information for the address register. The scaler is increased by one as each word is stored during the write cycle. When the

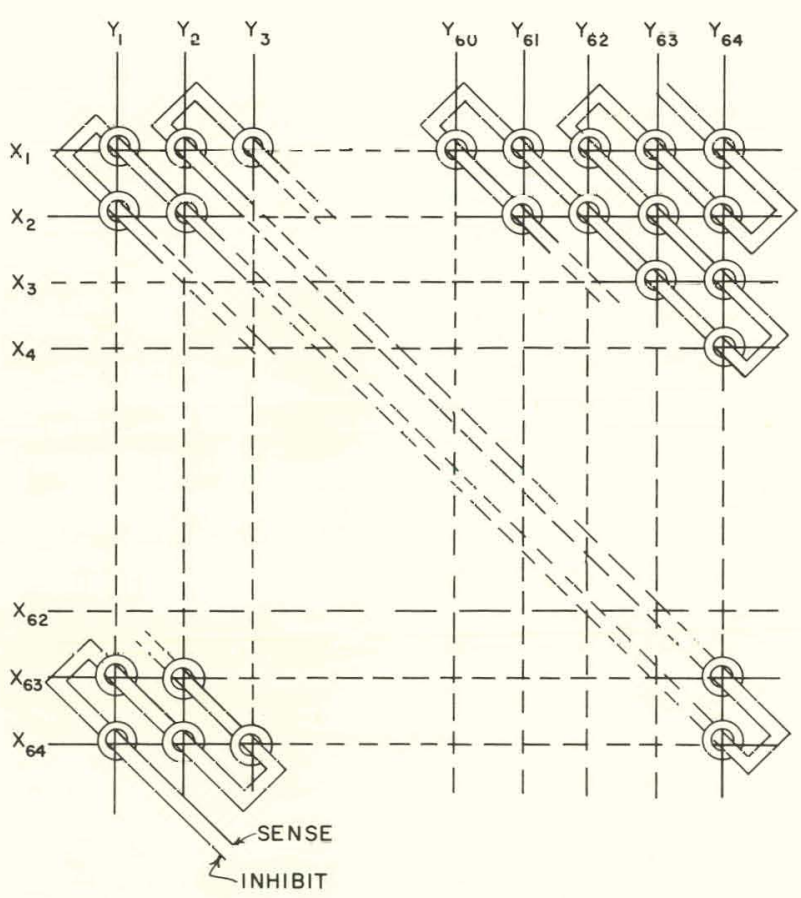

Figure 5. Simplified schematic of 4096-word $\times$ 48-bit magnetic core memory. 
memory readout is initiated by a readout command, the scaler is not reset but addresses the last word written, then scales down one at a time until the entire memory is read out. It should be noted that when a readout command is given, before readout is begun, two special words are written in the memory automatically. The last 12 bits of the second word contain the number of words that are stored in the memory. The remaining 84 bits may be used to record identifying information and other information such as the scaler numbers representing beam rate, etc.

Write and read control: Events are sequentially written into the memory until either the memory is full or an external readout mode command is supplied. This command usually comes from a predetermined timer signalling the end of an AGS pulse. There is also an adjustable minimum address flag which allows one to select a minimum number of words to be written in the memory before a readout can occur, regardless of readout command.

The system control logic automatically provides inhibit signals and disables input circuits as required when it is not ready to accept data.

\section{THE MAGNETIC TAPE TRANSPORTS}

These are Potter Model MT 120, operated at a speed of 112.5 in./sec. Packing densities available are $200,555.5$, or 800 characters/in. Output is written in the IBM binary format, each character consisting of 6 data bits and a parity check bit. The content of the memory is written as a single IBM "Record" and is followed by a longitudinal parity check character.

The dual transport control circuit permits one data handling system to use two magnetic tape transports alternately to avoid losses due to tape changing. In a typical case, one transport will write experimental data until it senses a low tape situation. After that, one more block of information is written on the same tape, an end-of-file mark is written, and the tape automatically rewinds.

The next block of information will be written by the second transport. A system of interlocks is provided to help avoid accidental writing over already recorded data.

\section{PARALLEL OPERATION}

The two 48-bit-wide units can be connected by a tieline cable to operate as one 96-bit, 4096-word unit. During the read mode the units act as one "master" and one "slave," the master providing all control signals and driving the tape transports and data link.

\section{EXPERIMENTS PLANNED WITH THIS SYSTEM}

\section{A. Elastic Scattering of 11 to 30-BeV/c $\pi^{ \pm}, p, \bar{p}$, and $K^{ \pm}$by Protons}

This is one of the first experiments planned to be done this year with the new data handling system. The experimental arrangement is given in Figure 6 . The angular range measured will be $\approx 1.5$ to $\approx 25 \mathrm{mrad}$, corresponding to $|t|$ ranging from 0.001 to $0.5(\mathrm{BeV} / \mathrm{c})^{2}$ spread over $20 t$ bins in each measurement.

Taking full advantage of the new data system, we expect in sorne high beam rate cases to record up to $1,000,000$ events $/ \mathrm{hr}$, of which about a tenth to a quarter are expected to be elastic. The polar scattering angle measurement will be good to 0.7 mrad, and the momentum of the forward scattered particle will be measured to within $0.8 \%$.

\section{B. Elastic Scattering of 11 to $21-\mathrm{BeV} / \mathrm{c}$ $\pi^{ \pm}, p, \bar{p}$, and $K^{ \pm}$by Protons \\ in the $|t|$ Range 0.7 to $3(\mathrm{BeV} / \mathrm{c})^{2}$}

Sonic spark chambers up to 1 meter in size with 4 probes/gap will be used. These chambers will have up to 3 gaps/unit and will allow automatic computer measurements of the position of thc tracks with a resolution estimated to be a fraction of a millimeter. The sonic time-of-flight will be measured by scualing a 5-megacycle clock. The binary bits from the scalers will be read into the new data handling system and transmitted to the Merlin computer for immediate on-line data processing. The planned arrangement of the experiment is given in Figure 7. Two sonic spark chambers after the hydrogen target will accurately measure thc direction of the forward scattered particle. Then a magnet followed by a third sonic chamber will determine its momentum to $\sim 0.6 \%$. Other sonic chambers will simultaneously measure the recoil $\theta$ angle to $\approx 0.7 \mathrm{mrad}$, which is a gain in $\theta$ resolution of an order of magnitude compared to our previous work, and the recoil $\varphi$ angle will be determined to $12 \mathrm{mrad}$, which is a gain over our previous $\varphi$ resolution by greater than a factor of 3 . 


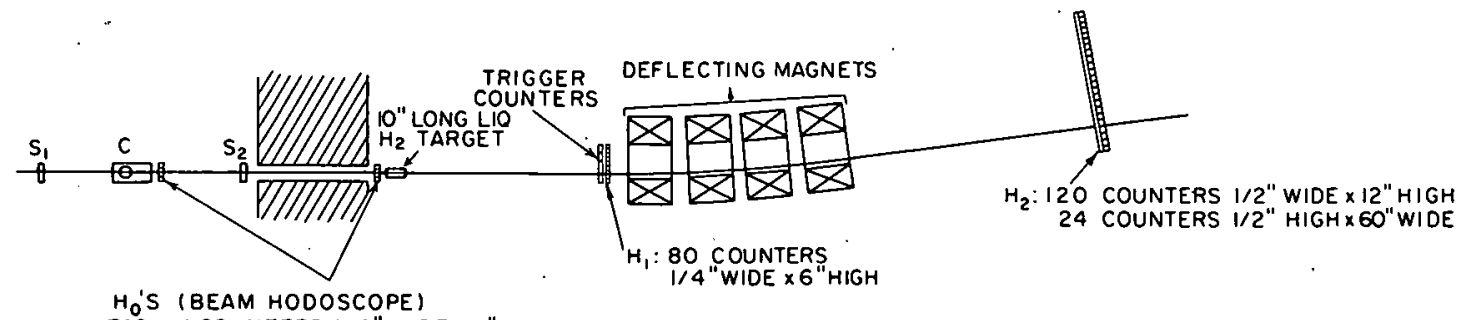

Ho'S (BEAM HODOSCOPE)

EACH 4 COUNTERS $1 / 4$ "WIOE $\times 1 "$ HIGH

AND 4 COUNTERS I"WIDE $\times 1 / 4$ "HIGH

FROM BEAM COUNTERS

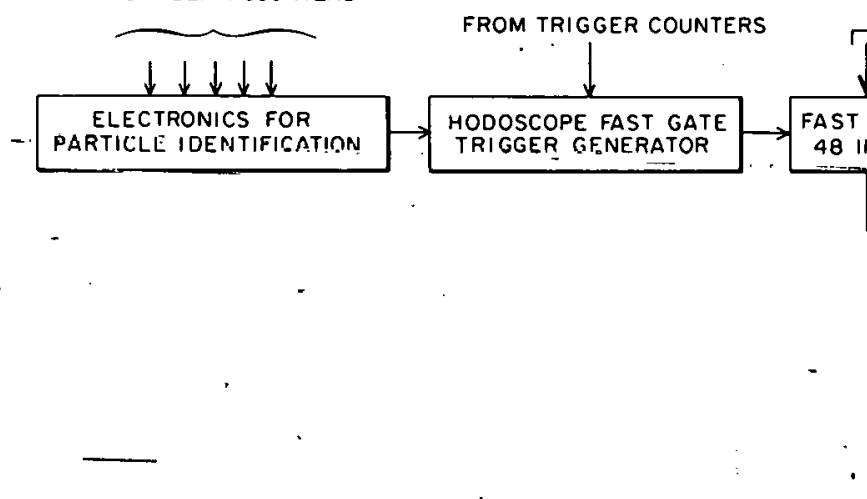

Figure 6. Small-angle elastic scattering AGS experimental set-up.
FROM HODOSCOPE COUNTERS $H_{0}$ 'S; $H_{1}$ AND $H_{2}$

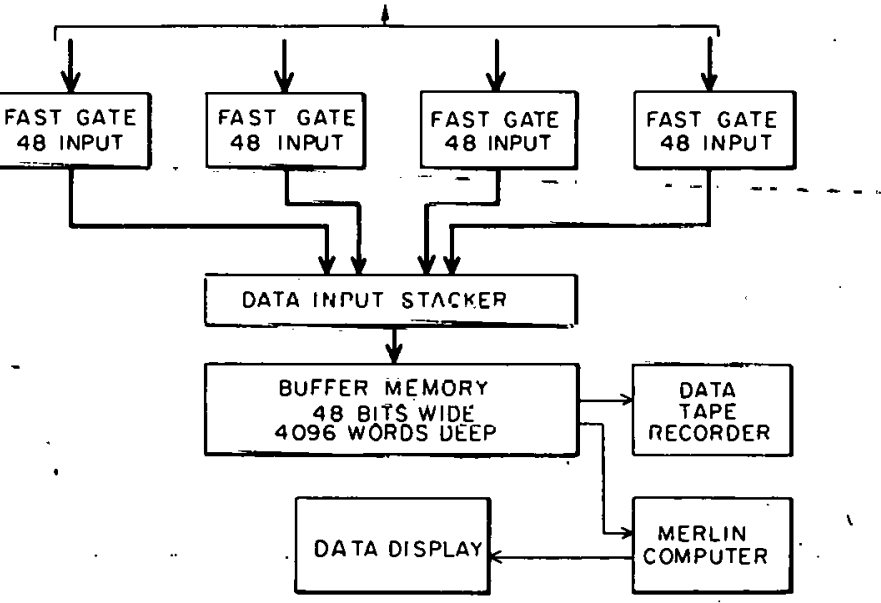

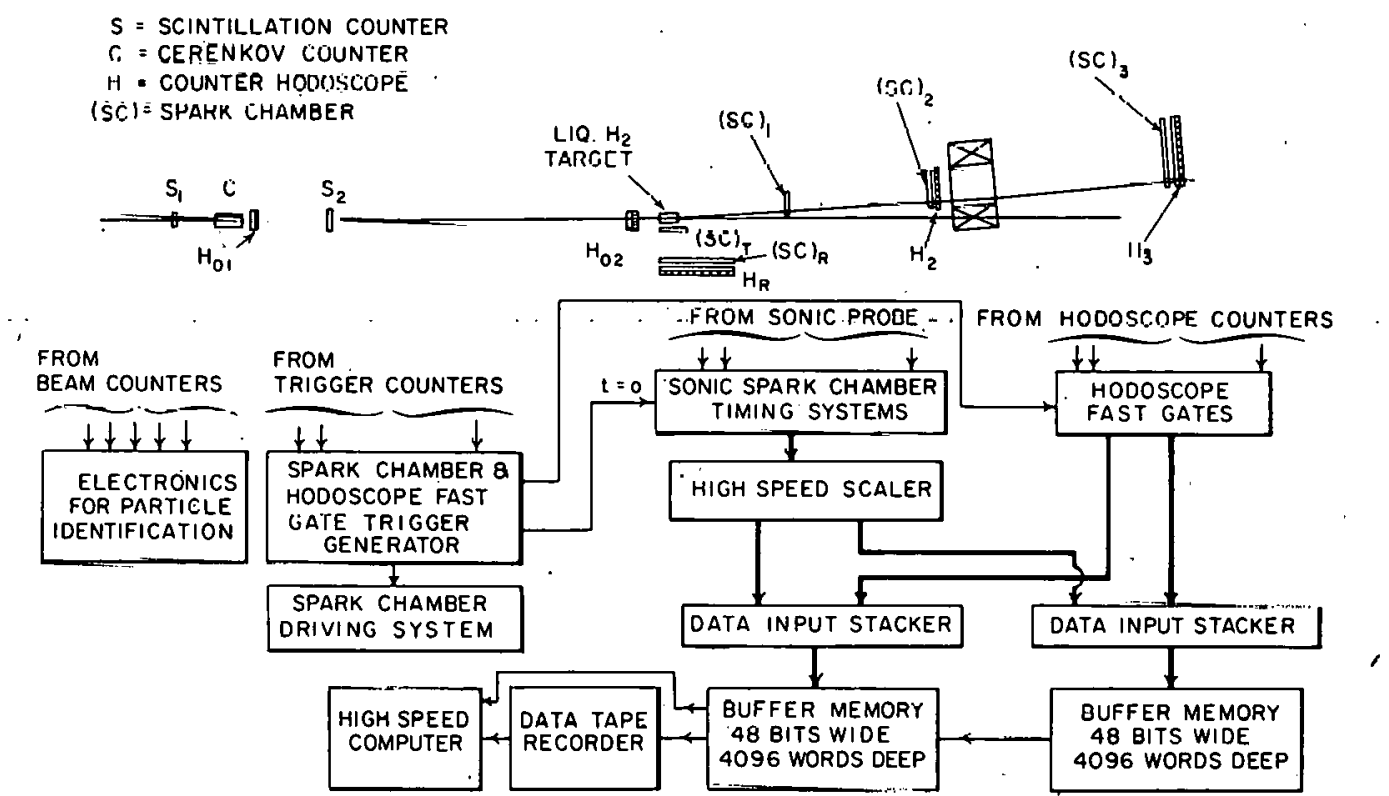

Figure 7. Elastic scattering AGS experimental set-up using sonic spark chambers and counter hodoscopes. 
This, together with the high magnetic resolution for the forward scattered particle which was not used at all previously, should give us essentially a negligible background error out to the highest $|t|$ measured.

The system contains hodoscope arrays behind sonic chambers to allow logic selection, and also, in cases in which the higher resolution of the sonic chamber is not needed, the higher data rates obtained with the scintillators can be utilized. Obviously wire and other digitized spark chambers may be substituted for the sonic chambers in higher rate situations.

\section{Other Experiments With This Data System}

It is obvious that other digitized chambers such as wire, etc., can be used with this system, which was designed to be suitable for use with any digitizable electronic signal generating detector. Furthermore, multiparticle inelastic interactions can be investigated with techniques of this type. We already have planned for a series of multiparticle inelastic experiments detecting up to 4 finalstate particles. Furthermore, it turns out that inelastic scattering is studied as a by-product in our smallangle scattering using a magnetic spectrometer. 